\title{
The clinical utility of combinatorial pharmacogenomic testing for patients with depression: a meta-analysis
}

\author{
Lisa Brown ${ }^{1}$, Oliver Vranjkovic ${ }^{1}$, James $\mathrm{Li}^{2}$, Kunbo Yu², Talal Al Habbab", Holly Johnson ${ }^{1}$, \\ Krystal Brown ${ }^{3}$, Michael R Jablonski ${ }^{1} \&$ Bryan Dechairo*,3 \\ ${ }^{1}$ Department of Medical Affairs, Myriad Neuroscience, Mason, OH 45040, USA \\ 2 Department of MMM Informatics, Myriad Genetics, Mason, OH 45040, USA \\ ${ }^{3}$ Department of Clinical Development, Myriad Genetics, Salt Lake City, UT 84108, USA \\ *Author for correspondence: Bryan.Dechairo@myriad.com
}

\begin{abstract}
Aim: To perform a meta-analysis of prospective, two-arm studies examining the clinical utility of using the combinatorial pharmacogenomic test, GeneSight Psychotropic, to inform treatment decisions for patients with major depressive disorder (MDD). Patients \& methods: The pooled mean effect of symptom improvement and pooled relative risk ratio (RR) of response and remission were calculated using a random effect model. Results: Overall, 1556 patients were included from four studies, with outcomes evaluated at week 8 or week 10. Patient outcomes were significantly improved for patients with MDD whose care was guided by the combinatorial pharmacogenomic test results compared with unguided care (symptom improvement $\Delta=10.08 \%, 95 \% \mathrm{Cl}: 1.67-18.50 ; \mathrm{p}=0.019$; response $\mathrm{RR}=1.40,95 \% \mathrm{Cl}: 1.17-1.67 ; \mathrm{p}<0.001$; remission RR $=1.49,95 \% \mathrm{Cl}: 1.17-1.89 ; \mathrm{p}=0.001)$. Conclusion: GeneSight Psychotropic guided care improves outcomes among patients with MDD.
\end{abstract}

First draft submitted: 29 October 2019; Accepted for publication: 31 March 2020; Published online: 17 April 2020

Keywords: clinical utility $\bullet$ combinatorial pharmacogenomics $\bullet$ depression $\bullet$ GeneSight $\bullet$ major depressive disorder - meta-analysis

Achieving response and remission is the goal of treating any mental health disorder. Unfortunately, patients suffering from major depressive disorder (MDD) have only a 50\% chance of reaching a clinically significant response with their first antidepressant medication, with even fewer reaching remission [1]. The rates of remission and response continue to decrease with each subsequent medication trial, which can lead to further challenges in treating depression [2]. Difficult-to-treat depression culminates in significant personal, financial and socioeconomic challenges that generate a great burden on the economy due to missed work, and decreases in productivity and quality of life [3]. Therefore, better tools are needed to more quickly help patients achieve clinical remission.

One promising option is the use of pharmacogenomics to guide treatment selection for patients with MDD $[4,5]$ and other psychiatric disorders [6,7]. Pharmacogenomics is an evaluation of how drug tolerability and efficacy is affected by variants in pharmacokinetic and pharmacodynamic genes (gene-drug interactions) [8]. Pharmacokinetic genes are responsible for coding proteins that metabolize medications and pharmacodynamic genes code for proteins involved in medication effect. Historically, genetic variants were analyzed on an individual gene basis to determine possible gene-drug interactions. For example, CYP450 2D6 is often evaluated to determine whether there are any gene-drug interactions affecting the metabolism of the tricyclic antidepressant nortriptyline [9]. However, it is now well known that medications may be affected by more than one pharmacokinetic and/or pharmacodynamic gene [10].

The National Institutes of Health has funded the Clinical Pharmacogenomics Implementations Consortium (CPIC) to write pharmacogenomics guidelines based on systematic reviews performed by subject matter experts [11]. Most studies have examined the impact of one gene, usually within the CYP450 family, on one drug [12]. However, there are some instances where CPIC guidance cites multiple genes for a single medication. For example, CPIC provides a detailed dosing guidance and algorithm for warfarin that includes the genotypes of CYP2C19 and 
VKORC1, two pharmacokinetic genes involved in warfarin metabolism [13]. CPIC also provides guidance for selective serotonin reuptake inhibitors (SSRIs) and tricyclic antidepressants based on the genotypes of CYP2D6 and CYP2C19. Although there is not clear CPIC guidance for SSRI prescribing when there is variation in both genes $[10,14]$, some commercial pharmacogenomic tests provide guidance by using algorithms to weigh and combine the effects of multiple variants and genes.

There is a growing body of literature on the use of pharmacogenomics in MDD; however, there are mixed results regarding the utility of this testing. While randomized controlled trials (RCTs) are considered the gold standard to evaluate the effectiveness of a test, there may be concerns regarding reproducibility, bias and study limitations that can affect the quality of evidence $[15,16$. This is particularly relevant in pharmacogenomic testing in depression, where trial results vary drastically depending on which specific test was utilized, the study population and patient outcomes evaluated. By combining similar studies into a meta-analysis, potential biases from individual studies can be minimized to provide more robust evidence. The importance of meta-analyses has been recognized by evidence frameworks such as Grading of Recommendations Assessment, Development and Evaluations and a hierarchy of evidence has been established using this or other frameworks [15,16]. For example, the Canadian Network for Mood and Anxiety Treatments [17] and the Agency for Healthcare Research and Quality [18] consider a meta-analysis as the highest level of evidence. Data produced from such studies are therefore an important component in informing practice guidelines.

Recently, Bousman $e t$ al. and Rosenblat $e t$ al. have published meta-analyses examining outcomes among patients with MDD who had access to the results of various commercial pharmacogenomic tests, with Bousman et al. including only RCTs [19,20]. Both meta-analyses found a significant association between the pharmacogenomics guided treatment and remission among patients with MDD [19,20]. However, both reports acknowledged the potential impact of differences between the pharmacogenomic tests, which may limit the generalizability of the meta-analysis findings $[19,20]$. The utility of each clinical pharmacogenomic test should depend on which genes are included, how genotypes and phenotypes are assigned, whether a single or combinatorial gene approach is used and the specific combinatorial algorithm utilized. As a result, the different tests are not comparable [21] and the results of a meta-analysis of the collective utility of pharmacogenomic testing do not directly reflect on the utility of any single test.

Here, we present a meta-analysis of four prospective, controlled clinical studies that evaluated the clinical utility of the combinatorial pharmacogenomic test GeneSight Psychotropic among patients with MDD who had at least one prior medication failure. All four studies evaluated multiple measures of patient outcomes (remission, response and symptom improvement) using the 17-item Hamilton Depression Rating Scale (HAM-D17) among patients whose medication selection was informed by the combinatorial pharmacogenomic test results (guided care) compared with unguided care. Analyses were also performed according to the study type, with a separate evaluation of all RCTs.

\section{Patients \& methods}

Selection criteria

We utilized the Preferred Reporting Items for Systematic Reviews and Meta-Analyses guidelines [22]. Two reviewers ( $\mathrm{T}$ Al Habbab and H Johnson) both independently searched MEDLINE/PubMed for published reviews, meta-analyses and primary studies evaluating the impact of pharmacogenomic testing on outcomes for patients with MDD. Search terms included "pharmacogenomics", "guided", "study", "antidepressant", "depression" and "clinician".

All identified reports were screened for inclusion based on two rounds of review. The first round of review included an evaluation of the abstract to identify studies that utilized the GeneSight Psychotropic test. The second round was based on evaluation of the following inclusion criteria via full-text reviews: two-arm, prospective studies evaluating the clinical utility of GeneSight Psychotropic; including patients $\geq 18$ years of age diagnosed with MDD and assessing depressive symptom improvement, response and/or remission using HAM-D17. Both open-label and RCTs were eligible for inclusion. The Risk of Bias Assessment Tool from Cochrane Collaboration, was used to evaluate a possible source of bias for all included articles [23].

\section{Statistical analysis}

Symptom improvement from baseline was measured by the percentage change in HAM-D17 from baseline. Mean percentage of symptom improvement, sample size for each treatment arm and pairwise comparison p-values from 

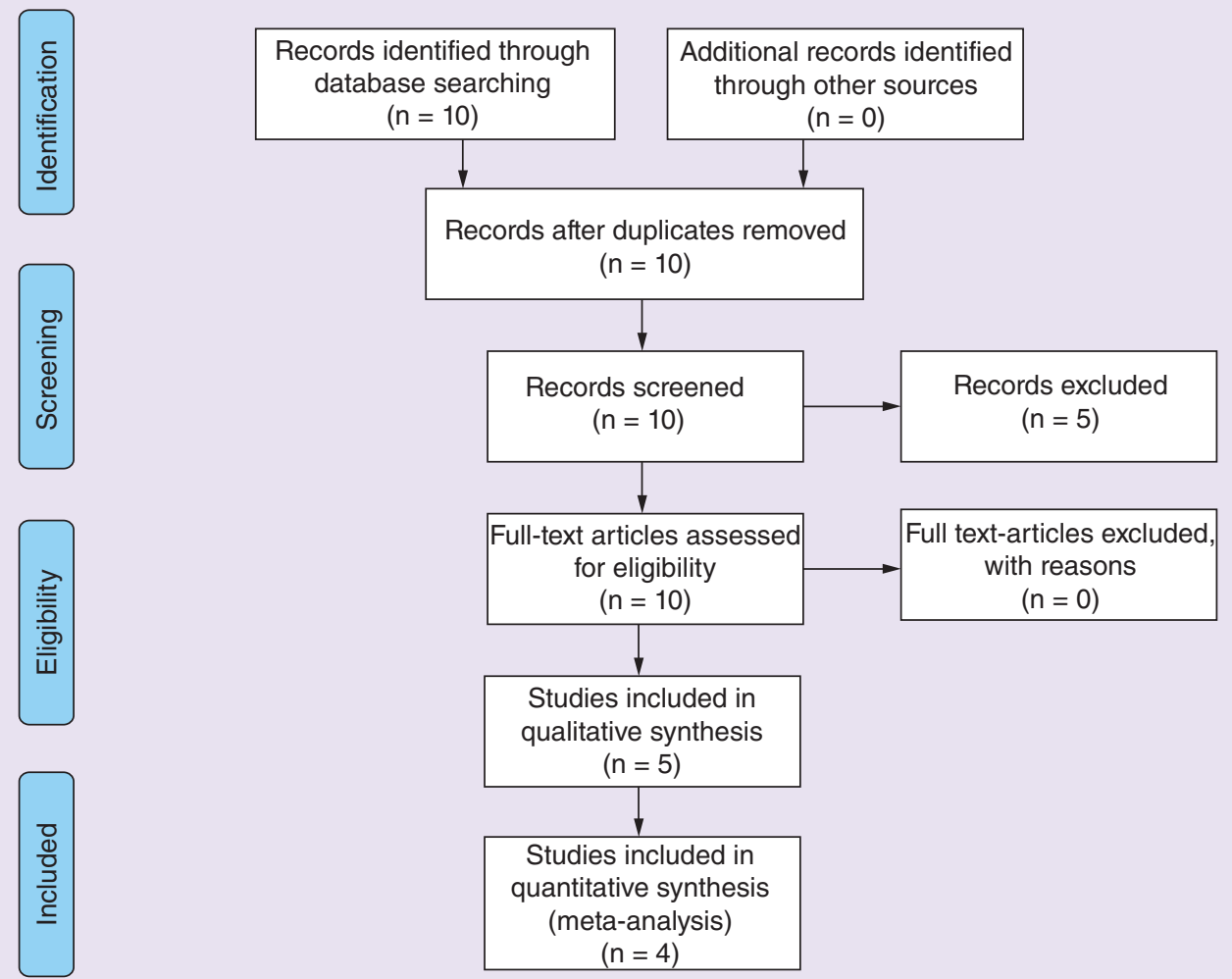

Figure 1. Preferred Reporting Items for Systematic Reviews and Meta-Analyses (PRISMA) flowchart for identifying clinical studies included in this meta-analysis.

each study were used for the meta-analysis. For response and remission, the relative risk ratio (RR) of guided care to the unguided care at week 8 or week 10 with 95\% lower and upper confidence intervals was determined for each study and was used for analyses. Meta-analyses were performed for all four studies, two open-label studies and two RCTs. To assess the influence of any given study, each study was omitted and meta-analyses were rerun to determine their influence on the pooled effect size.

The pooled mean effect of symptom improvement and pooled RR of response and remission for all four studies and omitting one study were calculated using a random effect model. The random effects model was utilized to address differences based on study design (open-label and RCTs) and between-study and within-study sampling errors. The pooled mean effect of symptom improvement and pooled RR of response and remission for the two open-label studies and two RCTs were calculated using a fixed effect model. The fixed effect model is appropriate as the study design and types were the same and were to estimate the same treatment effect. Heterogeneity in effect sizes across studies were tested using the Q-statistic and its magnitude was measured by the $\mathrm{I}^{2}$ statistic $\left(\mathrm{I}^{2}=25 \%\right.$, small heterogeneity; 50\%, moderate heterogeneity; 75\%, high heterogeneity) [18]. Comprehensive meta-analysis V2 was used for all meta-analyses.

\section{Results}

\section{Description of included studies}

In total, the systematic Preferred Reporting Items for Systematic Reviews and Meta-Analyses (PRISMA) literature review identified ten studies that met the search criteria (Figure 1). After the first round of review, three studies that did not evaluate GeneSight Psychotropic were excluded (Supplementary Table 1). Two additional studies were excluded in the second round of review as they did not meet the inclusion criteria (Supplementary Table 1). The remaining five publications were appropriate for inclusion (Figure $1 \&$ Table 1). Two of these publications reported on open-label trials (Hall-Flavin et al., 2012 and 2013 [30,31]) and two reported on RCTs (Winner et al. and Greden et al. [27,32]). A pooled analysis (Altar et al. [33]) of the two open-label trials and the RCT by Winner et al. 
Table 1. Description of the five publications on four studies evaluating the clinical utility of GeneSight Psychotropic in guiding treatment selection for patients with major depressive disorder.

\begin{tabular}{|c|c|c|c|c|c|c|c|}
\hline Study (year) & Study design & Eligibility & $\begin{array}{l}\text { Baseline cohort } \\
\text { characteristics }^{\dagger}\end{array}$ & Target genes & $\begin{array}{l}\text { Outcomes } \\
\text { reported }\end{array}$ & $\begin{array}{l}\text { Potential } \\
\text { sources of } \\
\text { bias }^{\ddagger}\end{array}$ & Ref. \\
\hline $\begin{array}{l}\text { Hall-Flavin } \\
\text { et al. (2012) }\end{array}$ & $\begin{array}{l}\text { - } 8 \text { week, prospective, } \\
\text { open-label study } \\
\text { - Two arms: guided } \\
\text { care vs unguided care } \\
\text { - Assessment points: } \\
\text { baseline, 2, } 4 \text { and } \\
8 \text { weeks }\end{array}$ & $\begin{array}{l}\text { Inclusion: } \\
\text { - Primary diagnosis of MDD } \\
\text { (DSM-IV criteria) } \\
\text { - HAM-D17 score } \geq 14 \\
\text { Exclusion: } \\
\text { - Diagnosis of bipolar } \\
\text { disorder type I, schizophrenia } \\
\text { and schizo-affective disorder }\end{array}$ & $\begin{array}{l}\text { Guided care ( } n=25 \text { baseline; } \\
22 \text { analyzed) vs unguided care } \\
\text { ( } n=26 \text { baseline; } 22 \text { analyzed) } \\
\text { - Age (years): } 42.1 \text { vs } 42.6 \text { ( } n \text { s) } \\
\text { - Sex ( } \% \text { female): } 54.5 \text { vs } \\
54.5 \text { ( } n \text { s) } \\
\text { - Baseline HAM-D17: specific } \\
\text { values not reported; Altar } \\
\text { et al. states } 20.6 \text { vs } 18.4 \text { (ns) } \\
\text { - Failed medication trials: } 6.0 \\
\text { vs } 6.7 \text { (ns) }\end{array}$ & $\begin{array}{l}\text { CYP1A2, CYP2C19, } \\
\text { CYP2D6, SLC6A4, } \\
\text { HTR2A }\end{array}$ & $\begin{array}{l}\text { Symptom } \\
\text { improvement }\end{array}$ & $\begin{array}{l}\text { Industry } \\
\text { funded, } \\
\text { recruitment }{ }^{\S} \text {, } \\
\text { patients and } \\
\text { clinicians } \\
\text { unblinded }\end{array}$ & [30] \\
\hline $\begin{array}{l}\text { Hall- Flavin } \\
\text { et al. (2013) }\end{array}$ & $\begin{array}{l}\text { - } 8 \text { week, prospective, } \\
\text { open-label study } \\
\text { - Two arms: guided } \\
\text { care vs unguided care } \\
\text { - Assessment points: } \\
\text { baseline, 2, } 4 \text { and } \\
8 \text { weeks }\end{array}$ & $\begin{array}{l}\text { Inclusion: } \\
\text { - } \geq 18 \text { years of age } \\
\text { - Diagnosed with MDD } \\
\text { (DSM-IV) } \\
\text { - HAM-D17 score } \geq 14 \\
\text { Exclusion: } \\
\text { - Diagnosis of bipolar type I, } \\
\text { schizophrenia, or } \\
\text { schizo-affective disorder }\end{array}$ & $\begin{array}{l}\text { Guided care ( } n=114 \text { baseline; } \\
n=72 \text { week } 8 \text { ) vs unguided } \\
\text { care ( } n=113 \text { baseline; } \\
93 \text { week } 8 \text { ) } \\
\text { - Age (years): } 41 \text { vs } 44 \text { (ns) } \\
\text { - Sex ( } \% \text { female): } 69.3 \text { vs } 77 \\
\text { (ns) } \\
\text { - Baseline HAM-D17: } 23 \text { vs } \\
22.5 \text { ( } n s) \\
\text { - Failed medication trials: } 3.6 \\
\text { vs } 4.7 \text { ( } p=0.021 \text { ) }\end{array}$ & $\begin{array}{l}\text { CYP1A2, CYP2C19, } \\
\text { CYP2D6, SLC6A4, } \\
\text { HTR2A }\end{array}$ & $\begin{array}{l}\text { Symptom } \\
\text { improvement, } \\
\text { response, } \\
\text { remission }\end{array}$ & $\begin{array}{l}\text { Industry } \\
\text { funded, } \\
\text { recruitment }{ }^{\S} \text {, } \\
\text { patients and } \\
\text { clinicians } \\
\text { unblinded }\end{array}$ & [31] \\
\hline $\begin{array}{l}\text { Winner } \\
\text { et al. (2013) }\end{array}$ & $\begin{array}{l}\text { - } 10 \text { week, prospective, } \\
\text { patient and rater } \\
\text { blinded, RCT } \\
\text { - Two arms: guided } \\
\text { care (GeneSight) vs } \\
\text { unguided care (TAU) } \\
\text { - Assessment points: } \\
\text { baseline, 4, } 6 \text { and } \\
10 \text { weeks }\end{array}$ & $\begin{array}{l}\text { Inclusion: } \\
\text { - Diagnosed with MDD or } \\
\text { DDNOS } \\
\text { - HAM-D17 score } \geq 14 \\
\text { Exclusion: } \\
\text { - Diagnosis of bipolar } \\
\text { disorder (any type), } \\
\text { schizophrenia, or } \\
\text { schizo-affective disorders } \\
\text { - Active diagnosis of } \\
\text { substance abuse or } \\
\text { dependence }\end{array}$ & $\begin{array}{l}\text { Guided care ( } n=26 \text { baseline; } \\
25 \text { week 10) vs unguided care } \\
\text { ( } n=25 \text { baseline; } 24 \text { week } 10) \\
\text { - Age (years): } 50.6 \text { vs } 47.8 \text { (ns) } \\
\text { - Sex ( } \% \text { female): } 69 \text { vs } \\
92 \text { ( } p=0.04) \\
\text { - Ethnicity ( } \% \text { Caucasian): } \\
96 \text { vs } 100 \text { (ns) } \\
\text { - Baseline HAM-D17: specific } \\
\text { values not reported; Altar } \\
\text { states } 21.6 \text { vs } 21.1 \text { (ns) } \\
\text { - Failed medication trials: } 4.3 \\
\text { vs } 4.5 \text { (ns) }\end{array}$ & $\begin{array}{l}\text { CYP1A2, CYP2C19, } \\
\text { CYP2D6, SLC6A4, } \\
\text { HTR2A }\end{array}$ & $\begin{array}{l}\text { Symptom } \\
\text { improvement, } \\
\text { response, } \\
\text { remission }\end{array}$ & $\begin{array}{l}\text { Industry } \\
\text { funded, } \\
\text { recruitment }{ }^{\S} \text {, } \\
\text { treating } \\
\text { clinician not } \\
\text { blinded }\end{array}$ & [32] \\
\hline $\begin{array}{l}\text { Altar } \\
\text { et al. (2015) }\end{array}$ & $\begin{array}{l}\text { - Meta-analysis of } \\
\text { Hall-Flavin 2012, } \\
\text { Hall-Flavin } 2013 \text { and } \\
\text { Winner } 2013\end{array}$ & NA & $\begin{array}{l}\text { Guided care }(n=119) \text { vs } \\
\text { unguided care }(n=139) \\
\text { - Baseline HAM-D17: } 22.4 \text { vs } \\
21.5 \text { (ns) }\end{array}$ & NA & $\begin{array}{l}\text { Symptom } \\
\text { improvement, } \\
\text { response, } \\
\text { remission }\end{array}$ & NA & [33] \\
\hline $\begin{array}{l}\text { Greden } \\
\text { et al. (2019) }\end{array}$ & $\begin{array}{l}\text { - } 8 \text { week, prospective, } \\
\text { patient and rater } \\
\text { blinded, RCT; } \\
\text { open-label extension } \\
\text { through } 24 \text { weeks. } \\
\text { - Two arms: guided } \\
\text { care vs unguided care } \\
\text { (TAU) } \\
\text { - Assessment points: } \\
\text { blinded: baseline, } 4 \\
\text { and } 8 \text { weeks; } \\
\text { unblinded: } 12 \text { and } 24 \\
\text { weeks }\end{array}$ & $\begin{array}{l}\text { Inclusion: } \\
\text { - } \geq 18 \text { years of age } \\
\text { - Diagnosed with MDD }(\geq 11 \\
\text { on QIDS-C16 and QIDS-SR16) } \\
\text { - Failed } \geq 1 \text { psychotropic } \\
\text { medication on the GeneSight } \\
\text { Psychotropic test in the } \\
\text { current depressive episode } \\
\text { Exclusion: } \\
\text { - Significant suicidal risk } \\
\text { - Some severe co-occurring } \\
\text { psychiatric or cognitive } \\
\text { disorders } \\
\text { - Unstable or significant } \\
\text { medical conditions }\end{array}$ & $\begin{array}{l}\text { ITT: guided care ( } n=760 \text { ) vs } \\
\text { unguided care ( } n=781 \text { ) } \\
\text { - Age (years): } 47.3 \text { vs } 48 \text { (ns) } \\
\text { - Sex ( } \% \text { female): } 71.6 \text { vs } 68.5 \\
\text { (ns) } \\
\text { - White ( } \%): 80 \text { vs } 82.6 \text { (ns) } \\
\text { - Baseline HAM-D17: } 20.49 \text { vs } \\
20.74 \text { (ns) } \\
\text { - Failed medication trials: } 3.44 \\
\text { vs } 3.52 \text { (ns) }\end{array}$ & $\begin{array}{l}\text { CYP1A2, CYP2B6, } \\
\text { CYP2C9, CYP2C19, } \\
\text { CYP2D6, CYP3A4, } \\
\text { SLC6A4, HTR2A }\end{array}$ & $\begin{array}{l}\text { Symptom } \\
\text { improvement, } \\
\text { response, } \\
\text { remission }\end{array}$ & $\begin{array}{l}\text { Industry } \\
\text { funded, } \\
\text { recruitment }{ }^{\S} \text {, } \\
\text { treating } \\
\text { clinician not } \\
\text { blinded }\end{array}$ & [27] \\
\hline
\end{tabular}

$\dagger$ Percentages or means are reported for all cohort characteristics.

$\ddagger$ Categories from the Risk of Bias Assessment Tool from Cochrane Collaboration that received a rating of 'high' are listed.

$\S$ Potential source of recruitment bias stems from subject referral for the study by the treating clinician.

DDNOS: Dissociative disorder not otherwise specified; DSM: Diagnostic and Statistical Manual of Mental Disorders; HAM-D17: 17-item Hamilton depression rating scale; ITT: Intent-to-treat; MDD: Major depressive disorder; NA: Not applicable; ns: Not significant; RCT: Randomized controlled trial; TAU: Treatment as usual.

also met the inclusion criteria because additional patient outcome information was included for the cohort in the Hall-Flavin et al. (2012) trial and Winner et al. (2013) RCT that was not published in the primary report; however, the publication was not considered a separate study because it included the same patient populations as Hall-Flavin 
et al. (2012) and Winner et al. (2013, [32]). As such, data from four unique studies reported in five publications were included in the meta-analysis.

All studies utilized the same combinatorial pharmacogenomic test, though the specific genes included in the test were different between some studies (Table 1). The primary objective in all included studies was an assessment of patient outcomes using HAM-D17. For most studies, patient outcomes were evaluated at week 8 , and Winner et al. assessed patient outcomes at week 10 . The four studies were prospectively enrolled and included a combinatorial pharmacogenomic guided care arm and an unguided care arm. Patients in the unguided care arm for all four studies received active treatment for their MDD that was not guided by the results of pharmacogenomic testing. A total of 1556 eligible subjects from the four unique clinical studies were examined. All four studies had approximately even distribution between the guided care and unguided care arms (Table 1).

\section{Risk of bias}

The four studies assessed were subject to multiple sources of bias (Table 1). The risk of bias for all the studies included here have been previously reported as part of the meta-analyses by Bousman et al. and/or Rosenblat et al. $[19,20]$. As the same framework was utilized here, our findings did not differ from what has been previously reported. In brief, selection, detection, attrition and reporting biases were all low for the two RCTs and the two open-label trials. The fact that treating physicians in both RCTs were not blinded to study arm resulted in high performance bias for these trials. Neither physicians nor patients were blinded to treatment group in the open-label studies. There was high recruitment bias for the open-label trials and RCTs, as physicians could refer subjects to be included in the trial. In addition, there was also a potential bias to these studies due to industry sponsorship and involvement in study design, execution and analysis.

\section{Symptom improvement}

The primary end point of all four studies was symptom improvement, measured as percent change from baseline HAM-D17 score to week 8 (Hall-Flavin et al., 2011 and 2012; Greden et al.) or 10 (Winner et al.). The heterogeneity in effect size across the four studies was significant, but moderate $\left(\mathrm{Q}=10.62 ; \mathrm{p}=0.014 ; \mathrm{I}^{2}=71.75\right.$; Figure 2A). The random-effects model suggests that symptom improvement was significantly better when the combinatorial pharmacogenomic test results were available to the physician, with HAM-D17 scores decreasing an additional 10.08\% (95\% CI: 1.67-18.50; $\mathrm{p}=0.019)$ from baseline to week 8/10 for guided care versus unguided care (Figure 2A). Overall, the guided care had a 33.8\% reduction in HAM-D17 score while the unguided care had a $23.7 \%$ reduction, representing a $43 \%$ improvement over the unguided care. Removal of either of the open-label studies from the analysis showed that symptom improvement was greater for the guided care versus unguided care, but the difference was no longer significant (Hall-Flavin et al., 2012; $\Delta=9.54,95 \%$ CI: $-1.09-20.17 ; \mathrm{p}=0.079$ and Hall-Flavin et al., 2013; $\Delta=5.76,95 \% \mathrm{CI}$ : -0.17-11.69; $\mathrm{p}=0.057$; Supplementary Figure 1A).

When the studies were grouped by trial design, symptom improvement was significantly larger for guided care compared with unguided care for the open-label studies $(\Delta=15.5,95 \% \mathrm{CI}: 8.72-22.29 ; \mathrm{p}<0.001)$ and the RCTs ( $\Delta=3.44 \%$, 95\% CI: 0.06-6.83; $\mathrm{p}=0.046$; Figure 3A). The magnitude of the difference was lower for the RCTs.

\section{Response}

Overall response based on HAM-D17 was also evaluated for all four studies, defined as at least a 50\% reduction in HAM-D17 score from baseline to week 8/10. The effect size of response was consistent across all four studies $\left(Q=2.43 ; \mathrm{p}=0.489, \mathrm{I}^{2}=0.000\right.$; Figure $\left.2 \mathrm{~B}\right)$. The pooled $\mathrm{RR}$ suggests that the guided care arm had a $40 \%$ higher response rate compared with the unguided arm $(\mathrm{RR}=1.40,95 \% \mathrm{CI}: 1.17-1.67$; $\mathrm{p}<0.001$; Figure 2B). The $\mathrm{RR}$ for response was relatively constant when each of the trials was systematically removed from the analysis, with the exception Greden et al. $(\mathrm{RR}=1.71,95 \% \mathrm{CI}: 1.17-2.49 ; \mathrm{p}=0.005)$; however, the RR for response remained significant regardless of which study was omitted (Supplementary Figure 1B).

Response was significantly higher among patients in the guided care arm for both the open-label trials $(\mathrm{RR}=1.72$, 95\% CI: 1.11-2.67; p = 0.016) and RCTs (RR = 1.34, 95\% CI: 1.10-1.62; p = 0.004, respectively; Figure 3B).

\section{Remission}

All four studies also evaluated remission, defined as HAM-D17 scores reaching $\leq 7$. The effect size of remission was consistent across the four studies $\left(\mathrm{Q}=0.539 ; \mathrm{p}=0.910, \mathrm{I}^{2}=0.000\right.$; Figure $\left.2 \mathrm{C}\right)$. The pooled $\mathrm{RR}$ suggests that patients who received combinatorial pharmacogenomic-guided care achieved $49 \%$ higher remission compared 


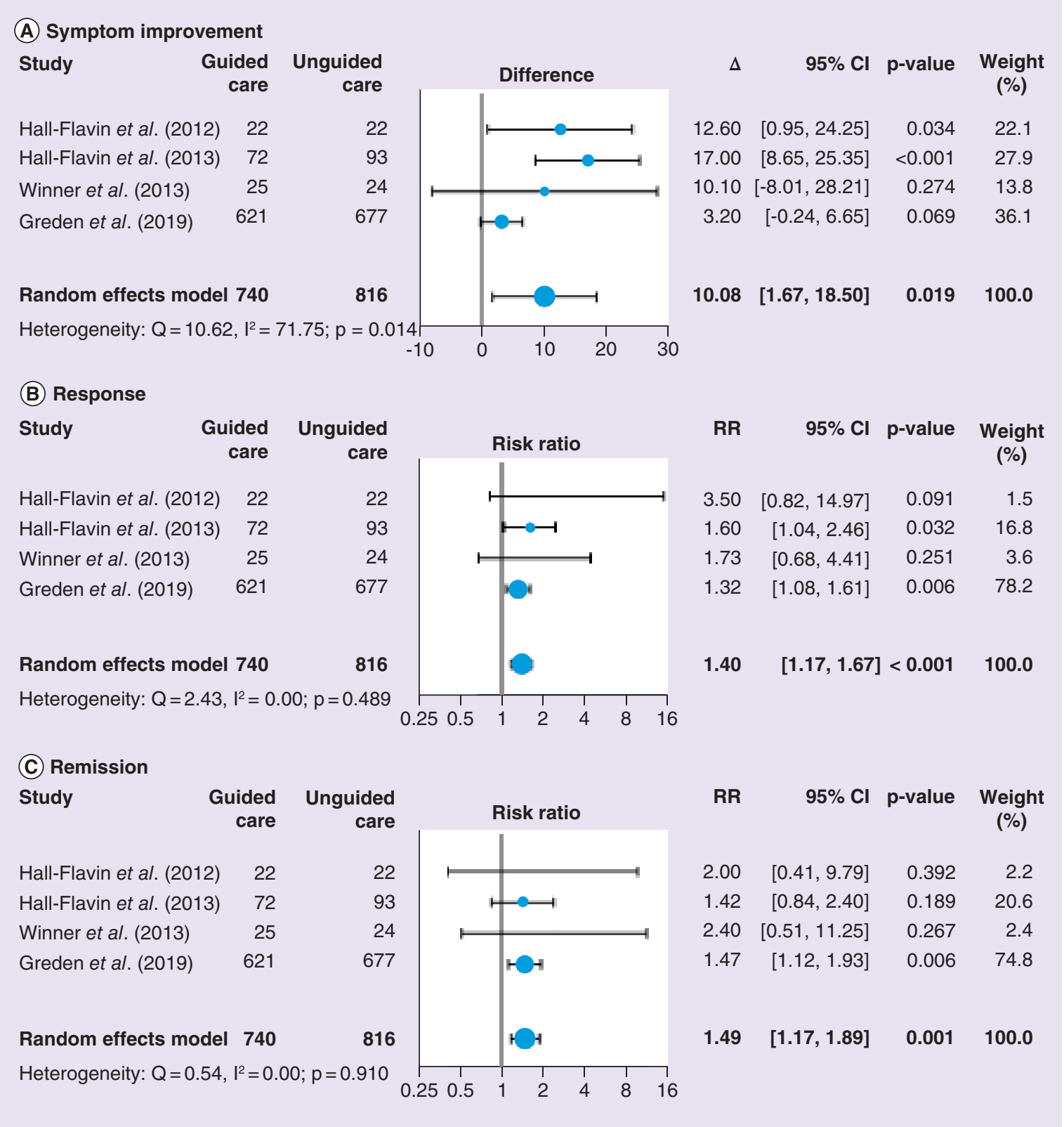

Figure 2. Forest plot of random-effects meta-analysis of four prospective, two-arm studies that examined the clinical utility of GeneSight Psychotropic in guiding treatment decisions for patients with major depressive disorder. (A) Average difference in symptom improvement, (B) RR for response and (C) RR for remission between guided and unguided care. Circle size indicates weight in overall analysis.

RR: Relative risk ratio.

unguided care $(\mathrm{RR}=1.49,95 \% \mathrm{CI}: 1.17-1.89 ; \mathrm{p}=0.001$; Figure $2 \mathrm{C})$. The $\mathrm{RR}$ for remission was relatively constant when each of the trials was systematically removed from the analysis, though remission was not significantly different when Greden et al. was removed ( $\mathrm{p}=0.075$; Supplementary Figure 1C).

The open-label studies did not exhibit significantly higher remission rates among the guided care arm compared with the unguided care arm $(\mathrm{RR}=1.47,95 \% \mathrm{CI}: 0.89-2.41 ; \mathrm{p}=0.130$; Figure $3 \mathrm{C})$. However, the rate of remission in the RCTs was $49 \%$ higher for guided care compared with unguided care $(\mathrm{RR}=1.49,95 \% \mathrm{CI}$ : 1.14-1.96; $\mathrm{p}=0.004)$. 
(A) Symptom improvement

\begin{tabular}{|c|c|}
\hline Study & $\begin{array}{r}\text { uided } \\
\text { care }\end{array}$ \\
\hline Hall-Flavin et al. (2012) & 22 \\
\hline Hall-Flavin et al. (2013) & 72 \\
\hline $\begin{array}{l}\text { Fixed effect } \\
\text { for open-lak }\end{array}$ & $s$ \\
\hline Winner et al. (2013) & 25 \\
\hline Greden et al. (2019) & 621 \\
\hline 8 & \\
\hline
\end{tabular}

(B) Response
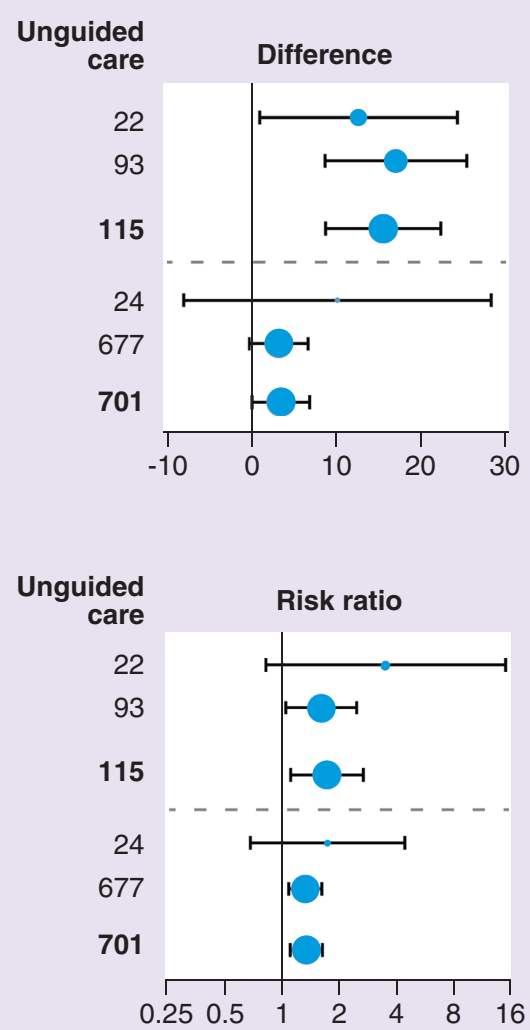

$\begin{array}{crrrr}\text { RR } & \text { 95\% Cl } & \text { p-value } & \begin{array}{c}\text { Weight } \\ \text { (\%) }\end{array} \\ 3.50 & {[0.82,14.97]} & 0.091 & 9.1 \\ 1.60 & {[1.04,2.46]} & 0.032 & 90.9 \\ 1.72 & {[1.11,2.67]} & 0.016 & 100.0 \\ 1.73 & {[0.68,4.41]} & 0.251 & 4.4 \\ 1.32 & {[1.08,1.61]} & 0.006 & 95.6 \\ 1.34 & {[1.10,1.62]} & 0.004 & 100.0\end{array}$

$12.60[0.95,24.25] \quad 0.034 \quad 33.9$

$17.00[8.65,25.35]<0.001 \quad 66.1$

$15.51[8.72,22.29]<0.001 \quad 100.0$

$10.10[-8.01,28.21] \quad 0.274 \quad 3.5$

$3.20 \quad[-0.25,6.65] \quad 0.069 \quad 96.5$

$\begin{array}{llll}3.44 & {[0.06,6.83]} & 0.046 & 100.0\end{array}$

\begin{tabular}{|c|c|}
\hline Study & $\begin{array}{l}\text { uided } \\
\text { care }\end{array}$ \\
\hline Hall-Flavin et al. (2012) & 22 \\
\hline Hall-Flavin et al. (2013) & 72 \\
\hline $\begin{array}{l}\text { Fixed effects model } \\
\text { for Open-Label studies }\end{array}$ & 94 \\
\hline Winner et al. (2013) & 25 \\
\hline Greden et al. (2019) & 621 \\
\hline $\begin{array}{l}\text { Fixed effects model } \\
\text { for RCTs }\end{array}$ & 646 \\
\hline
\end{tabular}

(C) Remission

\begin{abstract}
Study
Guided

Hall-Flavin et al. (2012) 22

Hall-Flavin et al. (2013) 72

Fixed effects model

for Open-Label studies 94

Winner et al. (2013) 25

Greden et al. (2019) 621

Fixed effects model

for RCTs
\end{abstract}

Unguided

care

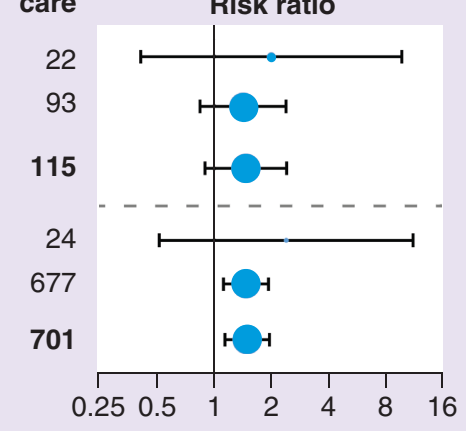

RR $\quad 95 \% \mathrm{Cl}$ p-value Weight

(\%)

$\begin{array}{llll}2.00 & {[0.41,9.79]} & 0.392 & 9.8\end{array}$

$\begin{array}{llll}1.42 & {[0.84,2.40]} & 0.189 & 90.2\end{array}$

$1.47[0.89,2.41] \quad 0.130 \quad 100.0$

$2.40[0.51,11.25] \quad 0.267 \quad 3.1$

$1.47 \quad[1.12,1.93] \quad 0.006 \quad 96.9$

$1.49[1.14,1.96] \quad 0.004 \quad 100.0$

Figure 3. Forest plot of fixed-effects meta-analysis for the open-label and randomized controlled trials. (A) Average difference in symptom improvement, (B) RR for response and (C) RR for remission between guided and unguided care. Circle size indicates weight in overall analysis.

RCT: Randomized controlled trial; RR: Relative risk ratio.

\section{Discussion}

As pharmacogenomic testing has emerged as a data-driven solution to improve treatment of MDD, it is necessary to ensure that utilization of these tests to inform medication selection is safe and effective. Recent meta-analyses have been performed for pharmacogenomic tests as a class [19,20], reporting that remission is significantly associated with pharmacogenomic-guided care. However, the generalizability of these findings is inherently limited due to differences among the pharmacogenomic tests that fundamentally alter the information provided regarding genedrug interactions. This is apparent in the substantial differences in the individual studies and in the meta-analyses themselves. Although meta-analyses provide a very high level of evidence regarding the utility of pharmacogenomic 
testing, a more appropriate approach is to perform meta-analyses for individual pharmacogenomic tests. Here, we performed a meta-analysis for studies reporting on a single combinatorial pharmacogenomic test, GeneSight Psychotropic, to provide more informative results regarding the clinical utility of that test.

This meta-analysis included prospectively enrolled, two-arm trials that utilized the combinatorial pharmacogenomic test to inform medication selection for patients with MDD who had failed at least one prior medication. Overall, these data show that patient care guided by this combinatorial pharmacogenomic test resulted in significantly better symptom improvement, response rates and remission rates compared with unguided care. Importantly, there was a very low degree of heterogeneity for response and remission and moderate heterogeneity for symptom improvement across all four studies, indicating that it is appropriate to combine these studies. As meta-analyses are recognized as the highest level of evidence by many organizations, this analysis provides important additional support that that difficult-to-treat patients with MDD can benefit from this combinatorial pharmacogenomic test [24-26]. It is important to note that there is overlap between the studies included in this meta-analysis and the two recent meta-analyses from Rosenblat et al. [20] and Bousman et al. [19] that reported on pharmacogenomics as a class. As such, care should be taken to not overinterpret the body of evidence available supporting pharmacogenomic testing as a class. However, the evidence provided for the combinatorial pharmacogenomic test in the meta-analysis presented here does provide strong evidence of the utility of that individual test.

The data presented here also provides additional insights into the impact of the placebo effect of pharmacogenomic testing and how that may impact the interpretation of clinical utility data. In the subanalyses by trial type, the magnitude of the difference in symptom improvement between arms decreased for the RCTs compared with the open-label trials. In addition, there was large variation in the difference between arms when each study was systematically removed, resulting in a moderate, but significant, degree of heterogeneity for the symptom improvement end point across the four studies. This heterogeneity may be unexpected for studies utilizing the same patient population and test; however, it is consistent with a placebo effect resulting in increased symptom improvement when the patient is aware that they are getting personalized genetic results. This sort of placebo effect was also found by Rosenblat $e t$ al., and was determined to be due to expectancy bias [20]. However, there was much less variation in the RR for response in the subanalyses by trial design and with systematic removal of each study presented here. This was even more apparent for remission, where there was virtually no difference in any of the subanalyses. This was also reflected in the heterogeneity analysis, which showed highly consistent results between studies for response and remission. Collectively, these data indicate that response and remission are more insulated from placebo effects, likely because they are more difficult to achieve. As such, the significant improvement in patient outcomes achieved with combinatorial pharmacogenomic-guided care represents a true improvement based on utilizing the test results to inform treatment selection.

The data included here provides continued support of the clinical utility of this combinatorial pharmacogenomic test in informing treatment selection for patients with MDD. This builds upon the recently reported findings from the Genomics Used to Improve Depression Decisions (GUIDED) RCT from Greden et al. [27]. GUIDED is the largest RCT performed to date examining the clinical utility of pharmacogenomic testing in mental health and reported significant improvements in response and remission rates. However, there have been several criticisms of the trial design. This includes concerns regarding the duration of the blinded period; however, the 8-week blinded period is consistent with US FDA draft guidance on studies of short-term treatment for MDD (treatment of a depressive episode), which indicates that 'antidepressants in established classes (e.g., SSRIs, serotonin-norepinephrine reuptake inhibitor [SNRIs]) typically need studies of 6-8 weeks duration to demonstrate efficacy' [28].

There have also been concerns that the treating clinician was not blinded in the GUIDED trial and for other RCTs on pharmacogenomic testing. It has been proposed that the lack of clinician blinding may impart a placebo effect to the patients based on physician expectation of success. While this may be a limitation, an ethical and viable alternative is not obvious [19]. For the combinatorial pharmacogenomic test evaluated here, clinician judgement is a critical component of patient care to inform possible treatment decisions including adding a medication, dropping a medication and/or changing the dose of an existing medication. Although it is difficult to assess whether there is any physician placebo effect in GUIDED, the robust remission end point is likely insulated from placebo effects, as discussed previously. As such, the significant findings for remission in the GUIDED trial and in this meta-analysis provide evidence of the clinical utility of GeneSight Psychotropic even in the absence of clinician blinding.

In addition to evidence of clinical utility, it is important that pharmacogenomic tests be also supported by robust evidence of analytical validity, clinical validity and economic utility in order to make them appropriate for clinical use [29]. Several prospective and retrospective studies have demonstrated the clinical validity and utility of this 
combinatorial pharmacogenomic test in patients with MDD who have failed at least one medication trial [30-35]. This includes five prospective clinical trials in two countries that were performed in collaboration with multiple academic centers [27,30-32,35], four of which were included in this study. In addition, the analytical validity [36] and cost-effectiveness [37-40] of the GeneSight Psychotropic test have also been demonstrated.

\section{Limitations}

This meta-analysis had some limitations. All of the included studies were industry-funded, potentially resulting in bias. However, non-industry trials of this sort have yet to be performed and it is therefore unknown what potential bias this may confer [17]. This analysis is also limited by a lack of ethnic diversity among the study populations, with the majority of patients being Caucasian. In addition, only one database (PubMed/Medline) was searched. Finally, data from two different types of studies were combined for the overall meta-analysis: open-label trials and RCTs. However, all studies had a similar study design and used the same primary outcomes and scales, which allowed for this combination. This is sort of meta-analysis design is not novel, as the recent Rosenblat et al. meta-analysis also combined open-label trials and RCTs [20]. Combining these data provides important insight into the utility in real-world settings (open-label) as well as blinded RCTs.

\section{Conclusion \& future perspective}

Although previous meta-analyses have demonstrated the utility of pharmacogenomic testing, the generalizability of those findings are limited by substantive differences in the individual pharmacogenomic tests. This meta-analysis of four studies reporting on the clinical utility of GeneSight Psychotropic testing demonstrates that utilization of this pharmacogenomic test to inform treatment decisions for patients with MDD with at least one prior medication failure is associated with improved patient outcomes compared with unguided care. This was true for all patient outcomes evaluated, including symptom improvement, response and remission. In addition, a separate analysis of the two RCTs that have evaluated the clinical utility of this test showed consistent results, with significant findings across all evaluated patient outcomes.

\section{Summary points}

- Up to $50 \%$ of patients with major depressive disorder do not reach clinical response during their first medication trial.

- Pharmacogenomic testing is a possible solution to improve treatment for depression by supporting data-driven treatment recommendations.

- There are many available pharmacogenomic tests, each with different testing approaches and varying levels of evidence supporting their clinical utility.

- Meta-analyses are recognized as the highest level of evidence by organizations such as the Canadian Network for Mood and Anxiety Treatments, and the Agency for Healthcare Research and Quality.

- Because it is not appropriate to evaluate the collective impact of pharmacogenomics as a class due to the significant differences between available tests, we performed a meta-analysis of the available evidence for the GeneSight Psychotropic test.

- Both open-label and randomized, controlled trials were included, with some potential sources of bias (i.e., industry sponsorship and potential recruitment bias).

- There was moderate heterogeneity between the studies for symptom improvement, but little to no heterogeneity for the response and remission end points.

- There was a significant improvement for patients who received GeneSight Psychotropic-guided care compared with unguided care for all outcomes evaluated (symptom improvement, response and remission).

- All outcomes evaluated were significantly improved when just the two randomized, controlled trials were evaluated.

- Overall, the meta-analysis presented here provides robust evidence of the clinical utility of GeneSight Psychotropic guided treatment for patients with major depressive disorder who have at least one prior medication failure.

Supplementary data

To view the supplementary data that accompany this paper please visit the journal website at: www.futuremedicine.com/doi/suppl/10.2217/pgs-2019-0157 
Financial \& competing interests disclosure

L Brown, O Vranjkovic, T Al Habbab, H Johnson and MR Jablonski are employed by Myriad Neuroscience. J Li, K Yu, K Brown and B Dechairo are employed by Myriad Genetics. The authors have no other relevant affiliations or financial involvement with any organization or entity with a financial interest in or financial conflict with the subject matter or materials discussed in the manuscript apart from those disclosed.

No writing assistance was utilized in the production of this manuscript.

Open access

This work is licensed under the Attribution-NonCommercial-NoDerivatives 4.0 Unported License. To view a copy of this license, visit http://creativecommons.org/licenses/by-nc-nd/4.0/

\section{References}

Papers of special note have been highlighted as: $\bullet$ of interest; $\bullet \bullet$ of considerable interest

1. Rush AJ, Trivedi MH, Wisniewski SR et al. Acute and longer-term outcomes in depressed outpatients requiring one or several treatment steps: a STAR*D report. Am. J. Psychiatry 163(11), 1905-1917 (2006).

2. Ghio L, Gotelli S, Marcenaro M, Amore M, Natta W. Duration of untreated illness and outcomes in unipolar depression: a systematic review and meta-analysis. J. Affect. Disord. 152-154, 45-51 (2014).

3. Gibson TB, Jing Y, Smith Carls G et al. Cost burden of treatment resistance in patients with depression. Am. J. Manag. Care 16(5), 370-377 (2010).

4. Arandjelovic K, Eyre HA, Lenze E, Singh AB, Berk M, Bousman C. The role of depression pharmacogenetic decision support tools in shared decision making. J. Neural Transm. (Vienna) 126(1), 87-94 (2017).

5. Bousman CA, Forbes $\mathrm{M}$, Jayaram $\mathrm{M}$ et al. Antidepressant prescribing in the precision medicine era: a prescriber's primer on pharmacogenetic tools. BMC Psychiatry 17(1), 60 (2017).

6. Ielmini M, Poloni N, Caselli I et al. The utility of farmacogenetic testing to support the treatment of bipolar disorder. Pharmacogenomics Pers. Med. 11, 35-42 (2018).

7. Ielmini M, Poloni N, Caselli I et al. The role of pharmacogenetics testing in the treatment of bipolar disorder: preliminary results. Minerva Psichiatrica 59(1), 10-15 (2018).

8. Corponi F, Fabbri C, Serretti A. Pharmacogenetics and depression: a critical perspective. Psychiatry Investig. 16(9), 645-653 (2019).

9. Dalen P, Dahl ML, Bernal Ruiz ML, Nordin J, Bertilsson L. 10-Hydroxylation of nortriptyline in white persons with $0,1,2,3$, and 13 functional CYP2D6 genes. Clin. Pharmacol. Ther. 63, 444-452 (1998).

10. Hicks JK, Bishop JR, Sangkuhl K et al. Clinical Pharmacogenetics Implementation Consortium (CPIC) guideline for CYP2D6 and CYP2C19 genotypes and dosing of selective serotonin reuptake inhibitors. Clin. Pharmacol. Ther. 98(2), 127-134 (2015).

11. Caudle KE, Klein TE, Hoffman JM et al. Incorporation of pharmacogenomics into routine clinical practice: the Clinical Pharmacogenetics Implementation Consortium (CPIC) guideline development process. Curr. Drug Metab. 15(2), 209-217 (2014).

12. Leckband SG, Kelsoe JR, Dunnenberger HM et al. Clinical Pharmacogenetics Implementation Consortium guidelines for $H L A-B$ genotype and carbamazepine dosing. Clin. Pharmacol. Ther. 94(3), 324-328 (2013).

13. Johnson JA, Caudle KE, Gong L et al. Clinical Pharmacogenetics Implementation Consortium (CPIC) guideline for pharmacogenetics-guided warfarin dosing: 2017 update. Clin. Pharmacol. Ther. 102(3), 397-404 (2017)

14. Hicks JK, Sangkuhl K, Swen JJ et al. Clinical Pharmacogenetics Implementation Consortium Guideline (CPIC) for CYP2D6 and CYP2C19 genotypes and dosing of tricyclic antidepressants: 2016 update. Clin. Pharmacol. Ther. 102(1), 37-44 (2017).

15. Guyatt GH, Oxman AD, Kunz R, Vist GE, Falck-Ytter Y, Schünemann HJ. What is 'quality of evidence' and why is it important to clinicians? BMJ 336(7651), 995 (2008).

16. Guyatt GH, Oxman AD, Vist GE et al. GRADE: an emerging consensus on rating quality of evidence and strength of recommendations. BMJ 336(7650), 924 (2008).

17. Kennedy SH, Lam RW, Mcintyre RS et al. Canadian Network for Mood and Anxiety Treatments (CANMAT) 2016 clinical guidelines for the management of adults with major depressive disorder: section 3. Pharmacological treatments. Can. J. Psychiatry 61(9), 540-560 (2016).

18. Clair J. Table 1 AHRQ scale of research grades and levels. In: Advances in Patient Safety: From Research to Implementation (Volume 3: Implementation Issues). Henriksen K, Battles J, Marks E (Eds). Agency for Healthcare Research and Quality (US), MD, USA (2005).

19. Bousman CA, Arandjelovic K, Mancuso SG, Eyre HA, Dunlop BW. Pharmacogenetic tests and depressive symptom remission: a meta-analysis of randomized controlled trials. Pharmacogenomics 20(1), 37-47 (2019).

- Meta-analysis of randomized controlled trials evaluating the clinical utility of pharmacogenomic testing.

20. Rosenblat JD, Lee Y, Mcintyre RS. The effect of pharmacogenomic testing on response and remission rates in the acute treatment of major depressive disorder: a meta-analysis. J. Affect. Disord. 241, 484-491 (2018). 
- Meta-analysis of open-label and randomized controlled trials evaluating the clinical utility of pharmacogenomic testing.

21. Bousman CA, Dunlop BW. Genotype, phenotypeand medication recommendation agreement among commercial pharmacogenetic-based decision support tools. Pharmacogenomics J. 18, 613-622 (2018).

22. Moher D, Liberati A, Tetzlaff J, Altman DG. Preferred reporting items for systematic reviews and meta-analyses: the PRISMA statement. PLoS Med. 6(7), e1000097 (2009).

23. Higgins Jpt GSE. Cochrane Handbook for Systematic Reviews of Interventions. Version 5.1.0 [updated March 2011] (2011). www.handbook.cochrane.org

24. Yetley EA, Macfarlane AJ, Greene-Finestone LS et al. Options for basing dietary reference intakes (DRIs) on chronic disease endpoints: report from a joint US-/Canadian-sponsored working group. Am. J. Clin. Nutr. 105(1), S249-S285 (2017).

25. Sterne JA, Hernán MA, Reeves BC et al. ROBINS-I: a tool for assessing risk of bias in non-randomized studies of interventions. BMJ 355, i4919-i4919 (2016).

26. Higgins JPT, Altman DG, Gøtzsche PC et al. The Cochrane Collaboration's tool for assessing risk of bias in randomized trials. BMJ343, d5928-d5928 (2011).

27. Greden JF, Parikh SV, Rothschild AJ et al. Impact of pharmacogenomics on clinical outcomes in major depressive disorder in the GUIDED trial: a large, patient and rater-blinded, randomized, controlled study. J. Psychiatr. Res. 111, 59-67 (2019).

-. Primary report of the GUIDED randomized controlled trial on the clinical utility of the combinatorial pharmacogenomic test, GeneSight Psychotropic.

28. US FDA. Major Depressive Disorder: Developing Drugs for Treatment - Guidance for Industry (Draft Guidance) (2018).www.fda.gov/ucm/groups/fdagov-public/@fdagov-drugs-gen/documents/document/ucm611259.pdf

29. Bousman CA, Hopwood M. Commercial pharmacogenetic-based decision-support tools in psychiatry. Lancet Psychiatry 3(6), 585-590 (2016).

30. Hall-Flavin DK, Winner JG, Allen JD et al. Using a pharmacogenomic algorithm to guide the treatment of depression. Transl. Psychiatry 2, e172 (2012).

-• Open-label study on the clinical utility of the combinatorial pharmacogenomic test, GeneSight Psychotropic.

31. Hall-Flavin DK, Winner JG, Allen JD et al. Utility of integrated pharmacogenomic testing to support the treatment of major depressive disorder in a psychiatric outpatient setting. Pharmacogenet. Genomics 23(10), 535-548 (2013).

-• Open-label study on the clinical utility of the combinatorial pharmacogenomic test, GeneSight Psychotropic.

32. Winner JG, Carhart JM, Altar CA, Allen JD, Dechairo BM. A prospective, randomized, double-blind study assessing the clinical impact of integrated pharmacogenomic testing for major depressive disorder. Discov. Med. 16(89), 219-227 (2013).

-• Randomized controlled trial on the clinical utility of the combinatorial pharmacogenomic test, GeneSight Psychotropic.

33. Altar CA, Carhart J, Allen JD, Hall-Flavin D, Winner J, Dechairo B. Clinical utility of combinatorial pharmacogenomics-guided antidepressant therapy: evidence from three clinical studies. Mol. Neuropsychiatry 1(3), 145-155 (2015).

- Pooled analysis of the two open-label trials and the randomized controlled trial by Winner et al. evaluating the clinical utility of the combinatorial pharmacogenomic test, GeneSight Psychotropic.

34. Altar CA, Carhart JM, Allen JD, Hall-Flavin DK, Dechairo BM, Winner JG. Clinical validity: combinatorial pharmacogenomics predicts antidepressant responses and healthcare utilizations better than single gene phenotypes. Pharmacogenomics J. 15(5), 443-451 (2015).

35. Tanner JA, Davies PE, Voudouris NC et al. Combinatorial pharmacogenomics and improved patient outcomes in depression: treatment by primary care physicians or psychiatrists. J. Psychiatr. Res. 104, 157-162 (2018).

36. Jablonski MR, King N, Wang Y et al. Analytical validation of a psychiatric pharmacogenomic test. Per. Med. 15(3), 189-197 (2018).

37. Winner J, Allen JD, Altar CA, Spahic-Mihajlovic A. Psychiatric pharmacogenomics predicts health resource utilization of outpatients with anxiety and depression. Transl. Psychiatry 3(3), e242 (2013).

38. Winner JG, Carhart JM, Altar CA et al. Combinatorial pharmacogenomic guidance for psychiatric medications reduces overall pharmacy costs in a 1 year prospective evaluation. Curr. Med. Res. Opin. 31(9), 1633-1643 (2015).

39. Brown LC, Lorenz RA, Li J, Dechairo BM. Economic utility: combinatorial pharmacogenomics and medication cost savings for mental healthcare in a primary care setting. Clin. Ther. 39(3), 592.e591-602.e591 (2017).

40. Benitez J, Cool CL, Scotti DJ. Use of combinatorial pharmacogenomic guidance in treating psychiatric disorders. Per. Med. 15(6), 481-494 (2018). 
